nerve power by electro-neurotone currents. I noted on several occasions after a few weeks' application quite a change in intellectual activity, as evidenced by improved memory. The currents were passed through the base of brain chiefly, by applications to the parotid regions on either side of the neck, and in the most casual manner, not in the least anticipating this practical result. 'The individuals operated on were over 60 years of age, and the improvement of memory was of such a character as in my humble opinion to be worthy of the closest scientific inquiry.

\section{REPORT OF TWO CASES OF AFEBRILE TYPHOID.}

CHAS. J. WHALEN, M.T., ILL.B., CHICAGO.

1 presume no one thing has aided us so much in the diagnosis of typhoid fever as the temperature chart. Since the use of the clinical thermometer the temperature has come to be the indication for diagnosis, treatment and prognosis. All the old and recent authorities place great emphasis on this symptom of the disease. Indeed, the temperature in typhoid is so absolutely essential for the estimation of each individual case that no scientific physician would treat one without regular measurements of the temperature.

It was formerly considered that typhoid fever had to be accompanied by elevation of temperature, and the rule that at some period of the disease the temperature is raised was supposed to be without an exception. That such a thing as afebrile tvphoid exists has been called to the attention of the profession by Liebermeister. I shall not enumerate the symptoms of this disease, but I wish to show that we may have absence of rise in temperature and yet the case be one of typhoid fever. Within the last few years I have seen patients with undoubted afebrile typhoid, and this has led me to give the subject consideration. My investigation has convinced me that the disease does occur in an endless number of types, and in this connection I desire to call attention to two cases of the afebrile form which came under my observation during the last sixteen months.

CASE 1.-J. E., a clerk, aged 23, whose previous health had been excellent, came to me Sept. 10, 1899, complaining of lassitude, headache, inaptitude for work, constipation quite pronounced, and loss of appetite. The above symptoms had been present for five days, and there was no temperature, but some splenic tenderness. He was given a cathartic with instructions to call again within forty-eight hours. At the end of this time he complained of having had a severe epistaxis on the morning of the sixth day, no temperature, the tongue dry and coated, and tenderness over the spleen more pronounced. I found both the diazo and Widal reactions positive, and this at once confirmed my suspicion of typhoid fever. On the eighth day there appeared a crop of five distinct rose spots. On the tenth there was quite marked iliac tenderness and meteorism present; the pulse was soft and beating 100 per minute. The patient was put to bed, where he remained for three weeks, and during this time his temperature was taken four times daily and the highest degree recorded was 99 . At the end of this time the patient was told that he might go home, but that he was to follow out instructions regarding diet, exercise, etc. On arriving home he disobeyed and partook of a large meal, walked several miles, spent the day and evening in visiting friends, and the following day felt weak and exhausted; on the next day he had headache, no desire for food and felt bad generally. $\mathrm{He}$ continued to grow worse, and, five days afterward I found him with mental torpor and dulness, his tongue and lips dry, a new crop of rose spots on the abdomen, and considerable meteorism present, with a large and tender spleen, temperature 102 and pulse 100. This patient, in his relapse, ran a typical course of severe typhoid fever, his temperature pursuing the stepladder rise and continuing high for four weeks, though he eventually recovered after being in bed two months.

CASE 2.-July 8, 1900, John R., a schoolboy, aged 17, consulted me because of lassitude, intense headache, weakness and gradual loss of appetite, nervousness, inability to sleep and occasional chilliness; he also complained of marked constipation. I found his tongue heavily coated, pulse 106, soft and slightly dicrotic, temperature normal, some iliac tenderness and meteorism present, a crop of rose spots on the abdomen and thorax, Widal and diazo reaction both positive. By July 20 he had improved generally, meteorism had nearly subsided, and he was beginning to crave food, no elevation of temperature had been noted, although it had been taken four times daily after the first visit. From this time on the patient gradually improved, and at the end of three weeks after first consulting me, barring a slight weakness, he was apparently well.

I was taught that typhoid fever had a characteristic course, a step-ladder rise in temperature continuing high for a period ranging from two to four weeks, declining gradually during the third and fourth. I am convinced that we may have genuine typhoid without any rise of temperature. Therefore, the typhoid of to-day is not the typhoid of von Niemeyer, Trousseau, Elint and others, for they portrayed a disease having a fairly constant train of symptoms, a fever with a characteristic course and other equally important conditions varying. Certainly ambulatory and afebrile types of the disease must have been very rare or else were not diagnosed in the practice of the older authors.

34 Washington Street.

A Hospital Steamer for the Philippines.-Major John S. Kulp, surgeon U. S. V., has recently reported the results of a voyage from Manila, on the army transport Pennsylvania, to bring sick men from the outlying islands to the general hospitals in that city. The vessel, a Philadelphia built, tripple-expansion, single-screw iron steamer, of 3343 tons capacity, left Manila Oct. 5, 1900, with a small cargo of subsistence and quartermaster's supplies and accommodation for the return of 160 sick soldiers. Everything necessary for the comfort, welfare and convenience of the sick was furnished promptly from the medical supply depot at Manila. The bunks were ironpipe frumes with woven-wire mattresses, all on the main deck, well ventilated and high above the water line. The vessel called at eighteen ports and brought off 155 patients, returning to Manila November 11, after a voyage of 2332 miles. Thirteen of the patients were affected with diarrhea, 46 with dysentery, 19 with malarial fever and 10 were sufferers trom gunshot wounds. No death occurred during the trip, although many of the cases when received were of a grave character. In every ease there was a marked improvement, and many were practically well by the end of the voyage. The object of the voyage was to determine whether or not it was practical to make use of one of the inter-island transports for the transportation of the sick during her regular trips. The result from an administrative standpoint was unsatisfactory. It proved that a shin devoted solely to the interests of the medical department was a necessity. Although the cargo was insignificant in amount the voyage was prolonged one-third on account of the delays caused by its delivery. Col. Greenleaf, chief surgeon of the Division of the Philippines, states that authority has been received from the U. S. secretary of war to purchase a lightdraught ship for use as an inter-island hospital transport, and that measures are now on foot to effect this object, which will solve satisfactorily the question of furnishing the provincial military hospitals with supplies and removing their sick when necessary. 